Old Dominion University

ODU Digital Commons

VMASC Publications

Virginia Modeling, Analysis \& Simulation Center

2014

\title{
Generic Incident Model for Investigating Traffic Incident Impacts on Evacuation Times in Large- Scale Emergencies
}

\author{
Andrew J. Collins \\ Old Dominion University, acollins@odu.edu \\ Peter Foytik \\ Old Dominion University,pfoytik@odu.edu \\ Erika Frydenlund \\ Old Dominion University, efrydenl@odu.edu \\ R. Michael Robinson \\ Old Dominion University, rmrobins@odu.edu \\ Craig A. Jordan \\ Old Dominion University, cajordan@odu.edu
}

Follow this and additional works at: https://digitalcommons.odu.edu/vmasc_pubs

Part of the Civil Engineering Commons, Emergency and Disaster Management Commons, Transportation Commons, and the Transportation Engineering Commons

\section{Repository Citation}

Collins, Andrew J.; Foytik, Peter; Frydenlund, Erika; Robinson, R. Michael; and Jordan, Craig A., "Generic Incident Model for Investigating Traffic Incident Impacts on Evacuation Times in Large-Scale Emergencies" (2014). VMASC Publications. 24.

https://digitalcommons.odu.edu/vmasc_pubs/24

\section{Original Publication Citation}

Collins, A. J., Foytik, P., Frydenlund, E., Robinson, R. M., \& Jordan, C. A. (2014). Generic incident model for investigating traffic incident impacts on evacuation times in large-scale emergencies. Transportation Research Record, 2459, 11-17. doi:10.3141/2459-02

This Article is brought to you for free and open access by the Virginia Modeling, Analysis \& Simulation Center at ODU Digital Commons. It has been accepted for inclusion in VMASC Publications by an authorized administrator of ODU Digital Commons. For more information, please contact digitalcommons@odu.edu. 


\title{
Generic Incident Model for Investigating Traffic Incident Impacts on Evacuation Times in Large-Scale Emergencies
}

\author{
Andrew J. Collins, Peter Foytik, Erika Frydenlund, R. Michael Robinson, \\ and Craig A. Jordan
}

\begin{abstract}
Traffic incidents cause a ripple effect of reduced travel speeds, lane changes, and the pursuit of alternative routes that results in gridlock on the immediately affected and surrounding roadways. The disruptions caused by the secondary effects significantly degrade travel time reliability, which is of great concern to the emergency planners who manage evacuations. Outcomes forecast by a generic incident model embedded in a microscopic evacuation simulation, the Real-Time Evacuation Planning Model (RtePM), were examined to quantify the change in time required for an emergency evacuation that results from traffic incidents. The incident model considered vehicle miles traveled on each individual segment of the studied road network model. The two scenarios considered for this investigation were evacuations of $(a)$ Washington, D.C., after a simulated terrorist attack and $(b)$ Virginia Beach, Virginia, in response to a simulated hurricane. These results could help the emergency planning community understand and investigate the impact of traffic incidents during an evacuation.
\end{abstract}

Traffic incidents cause a ripple effect of reduced travel speeds, lane changes, and the pursuit of alternative routes that results in gridlock on the immediately affected and surrounding roadways. The disruptions caused by the secondary effects significantly degrade travel time reliability, which is of great concern to the emergency planners who manage evacuations.

Little extant literature and even fewer predictive models address the effects of traffic incidents on evacuation duration. This study derives multiple regression models from limited data sets of different large-scale evacuation scenarios with the Real-Time Evacuation Planning Model (RtePM). The results of these regression models are compared with the results of previous evacuation studies to examine the feasibility of developing generalizable models of large-scale evacuation duration as a result of traffic incidents. The authors propose a simple, non-data-intensive traffic incident model to address criteria for the simplicity, scalability, time constraints, and universal funding shortages of evacuation planning models, as Matherly et al. describe in A Transportation Guide for All-Hazards Emergency Evacuation (1).

Virginia Modeling Analysis and Simulation Center, Old Dominion University, 1030 University Boulevard, Suffolk, VA 23435. Corresponding author: A. J. Collins, ajcollin@odu.edu.

Transportation Research Record: Journal of the Transportation Research Board, No. 2459, Transportation Research Board of the National Academies, Washington, D.C., 2014, pp. 11-17.

DOI: $10.3141 / 2459-02$
In the remainder of this paper, after a discussion of related literature and the RtePM microscopic evacuation model, four multivariate regression models will be used to analyze the effects of traffic incidents in two large metropolitan areas.

\section{BACKGROUND}

In its Manual on Classification of Motor Vehicle Traffic Accidents, the American National Standards Institute defines an accident as a situation in which injury or damage occurs to one or more motor vehicles that is not caused by a natural cataclysm (e.g., landslide, flood, or earthquake) (2). The National Highway Traffic Safety Administration calls this definition a crash. An incident is any disruptive event that happens on or near a road facility, including accidents or other types of events (e.g., a stall, debris, or road kill). Traffic incident modeling and the relevant modeling factors are briefly described in the next section.

\section{Traffic Incident Modeling}

Most recent traffic incident modeling research prioritizes the prediction of incident occurrence over the analysis of its effects (3-5). These approaches usually require vast amounts of data and do not satisfy the requirements for generalizability (1). Modeling paradigms used for incident modeling traditionally include mathematical programming and linear regression.

Chen and Xiao, for example, used linear programming to describe the real-time rerouting of evacuations around incidents with intelligent traffic signals $(6)$. Because of the complexity of the linear program, the polynomial time-bounded algorithm could process only up to 100 evacuees. Computational requirements render mathematical programming unfeasible for large-scale problems such as the evacuation of hundreds of thousands of people; Collins et al. discuss the limitations of practical mathematical programming (7).

Linear regression also has been used previously to predict traffic incidents in traffic incident analysis, as in the negative binomial-based regression model of Abdel-Aty and Radwan (8) and the hierarchical regression model (i.e., a regression model embedded in a regression model) of Huang et al. (9). Both applications of linear regression focus on incident prediction, whereas the regression models developed in this paper focus on the impacts of traffic incidents on evacuation time. Murray-Tuite and Mahmassani (10) and Liu et al. (11) also apply mathematical programming to evacuation modeling. 
Previous research on the impacts of travel demand in evacuations includes the work of Pel et al., who used the EVAQ deterministic simulation to investigate several driving factors on the evacuation duration of a scenario based in Rotterdam, Netherlands (12). The model did not consider traffic incidents. Wang et al. investigated the impact of human factors on evacuation duration by using systems dynamics and focus on the spread of panic in an evacuation event of 1,500 people (13). Robinson and Khattak $(14,15)$, Robinson (16), and Robinson et al. (17) examined evacuees' decision-making processes (e.g., whether to evacuate, whether to reroute around congestion, and the impact of roadside information signals). Research by Murray-Tuite and Mahmassani includes human factors, such as the need to rendezvous with family members before leaving the area (18). Quarantelli presents other research into human behavior during an evacuation $(19,20)$.

Robinson and Khattak considered the impacts of traffic incidents on evacuation duration, and their work is compared with the models derived in this paper (21). They used Citilabs' Cube Avenue mesoscopic simulation engine with historical incident data from Virginia's Hampton Roads (HR) region, whereas the model presented here uses a generic traffic incident rate. The scenarios described in this paper contain hundreds of thousands of evacuees and were implemented with the RtePM microsimulation model.

The generic traffic incident rate model implemented in RtePM was derived from publicly available national-level data to determine an incident probability per vehicle miles traveled (VMT) (22, p. 94); Collins et al. derived this formula (23). The generic incident model consists of two parts. The first determines whether an incident occurred on a road segment (a smaller unit than a road link, which could be composed of multiple segments) by using the VMT value in the previous time step (usually $1 \mathrm{~h}$ ). The second determines the impact of a traffic incident on other vehicles in the segment throughout the incident duration (usually limited to one time step); this impact includes reductions in available lanes and maximum speed. [Some limitations and assumptions of this approach (i.e., only one incident per segment per time step) are discussed later.] The approach results in the following formula:

$$
P=1-(1-p)^{\mathrm{VMT}}
$$

where $P$ and $p$ are the standard and fixed probabilities of an incident occurring per VMT, respectively. Collins et al. present information on the exact derivation and data sources for both of these parts of the model (23); traffic incident rates are discussed later, in the variables section.

\section{Parsimony of Independent Variables}

The modeling of traffic incidents during an evacuation scenario could encompass a wide range of factors, most of which relate to road geometry. When only on- and off-ramps are considered, the factors that contribute to accidents fall broadly into four categories: ramp length, distance between ramps, sight distance and signage, and exit ramp design (24). A significant amount of research has been conducted in these areas to understand the relationship between ramp geometry and traffic incident rates. For instance, McCartt et al. find that short-curve ramps account for a disproportionate number of crashes (25). Likewise, decreased distance between interchanges increases crashes, presumably because drivers are presented with more decision points (26). Limited sight distance caused by a small horizontal curvature angle on ramps and lack of appropriate signage also can increase the occurrence of traffic incidents $(24,26,27)$.

Several researchers have contributed to the study of road curvature on segments of urban and rural roadways. Results in this area are far less decided than in the ramp studies. Accurately and adequately measuring curvature is a complex task. In a study of the United Kingdom and Wales, Haynes et al. explain that contradictory results in this area of study result from discrepancies in measurement, methods of data collection, and even a common understanding of what constitutes a bend in the road (28). In a study of the United Kingdom, Wang et al. found that "wards with more curved roads have fewer casualties," even though this finding is based on mainly urban roads and the density of curves in a given area (29). Wang et al. believe that drivers are more careful in areas with many curved roads, particularly when these roads are through residential or commercial areas but do not discuss curvature on other types of roads or give specific accident statistics (29). However, in a study of New Zealand's roadways, Haynes et al. found initial measurements indicating that in a 10-year period up to 2005, "Approximately half of the crashes were recorded on straight sections, with $22 \%$ on easy curves, $24 \%$ on moderate curves and $4 \%$ on severe curves" (30). Ultimately, Haynes et al. concluded that the Wang et al. study results may be correct-but only when applied to urban roads (i.e., accident rates may be reduced on urban roads with more curves, but not necessarily elsewhere). Haynes et al. also suggest that problems with these types of curvature studies result from the lack of statistical power because small sample sizes are spread over large geographic areas (30).

Beyond crashes related to ramp configuration and conflicting research results about the effects of road curvature on traffic incidents, current transportation research yields few results applicable to a parsimonious evacuation model. This study acknowledges the existence of research suggesting that traffic incident rates are affected by road geometry. The study intends to provide a generalizable model for emergency planners that cannot, by its nature, include all aspects of road geometry and its intersections with human behavior and driver decision-making behavior during an evacuation scenario. Consideration of these factors intentionally is left to computationally intense, large-scale models in use for long-term event forecasting and planning. To confine the scope of this model to its original intent, the authors make broad generalizations about the nature of traffic incidents, using settings in the simulation software (outlined later).

\section{Real-Time Evacuation Planning Model}

Funded by the Science and Technology Directorate of the U.S. Department of Homeland Security, the RtePM is a web-based U.S. government software application developed in response to emergency managers' desires for a quick, user-friendly tool to estimate the time required to evacuate an area after a natural or human-induced disaster (www.rtepm.vmasc.odu.edu). The Johns Hopkins University Applied Physics Laboratory led initial prototype development, which included the use of a novel car-following model developed by Gang-Len Chang at the University of Maryland. In fall 2012, the Virginia Modeling, Analysis, and Simulation Center at Old Dominion University assumed responsibility for RtePM development. The RtePM model has been independently verified and validated (31).

The RtePM draws on census, proprietary road network, and commercial data and combines different modeling techniques to simulate an evacuation [e.g., evacuees determine routes according to 
an $\mathrm{A}^{*}$-search algorithm (32)]. The RtePM is a microlevel simulation in which individual vehicles respond to the environment in an autonomous way (i.e., they stop at signal intersections and determine their own evacuation routes). Users can modify many factors, including roadway contraflow, lane closures, vehicle occupancy, and population changes as well as overlay geographical data depicting natural and human-caused disaster scenarios. The RtePM provides time estimates required for user-defined evacuations as part of the standard output. Collins et al. completely describe and validate the traffic incident model used in RtePM (23).

\section{METHODOLOGY}

The researchers ran several thousand stochastic simulations under different variable conditions (i.e., traffic incidents and evacuation response rates) with the RtePM generic incident model for the two scenarios: a terrorist attack on Washington, D.C., and a hurricane in Virginia Beach, Virginia. Multivariate regression models then were used to investigate the impact of incidents on evacuation times. Everitt and Dunn provide an introduction to multivariate statistical analysis (33).

\section{Scenarios}

The first scenario reflects an evacuation in response to a hypothetical terrorist attack on Washington, D.C., to the surrounding national capital region (NCR). This region was chosen for its high traffic volume originating from a single, centralized area to examine the flow of hundreds of thousands of individually modeled vehicles in all directions. The second scenario represents the evacuation of Virginia Beach through the metropolitan HR area in response to a hurricane. This area was chosen because of the many complicating features of the road

network, including five major tunnels, more than 1,200 bridges, both rural and urban areas, and significant congestion.

Each scenario represents a large-scale, city-level evacuation to capture high traffic incident rates and their subsequent impacts. The RtePM microlevel simulation engine takes into account factors such as seasonal populations, which are explicitly included; background traffic also is accounted for as an effect on the existing modeled vehicles in the simulation. The expected number of traffic incidents was about the same in both scenarios (approximately 50 traffic incidents per evacuation event) because of the total VMTs in the evacuation. The similar number of expected traffic incidents in both scenarios provides a basis to compare these two geographically distinct regions.

\section{Scenario 1. Washington, D.C.}

On the basis of 2010 U.S. Census data, the model was initialized to evacuate 848,000 nighttime residents, all of whom were assumed to leave by private vehicle; pedestrians and public transportation were not considered. Vehicles carried 2.5 people on average, resulting in 339,000 vehicles in the microsimulation (14). Evacuees moved through the transportation network of nearly 10,000 road segments from their starting locations to one of 10 user-defined endpoints (Figure 1a). On reaching the endpoint, the vehicles were considered to have been evacuated. The RtePM estimated the evacuation time to be $10.4 \mathrm{~h}$ with no incidents and an 8 -h response time.

\section{Scenario 2. Virginia Beach}

The Virginia Beach scenario modeled the evacuation of that city before a hurricane. The scenario was chosen because of the wealth of existing studies of evacuations in the region $(14-17,21)$. On the

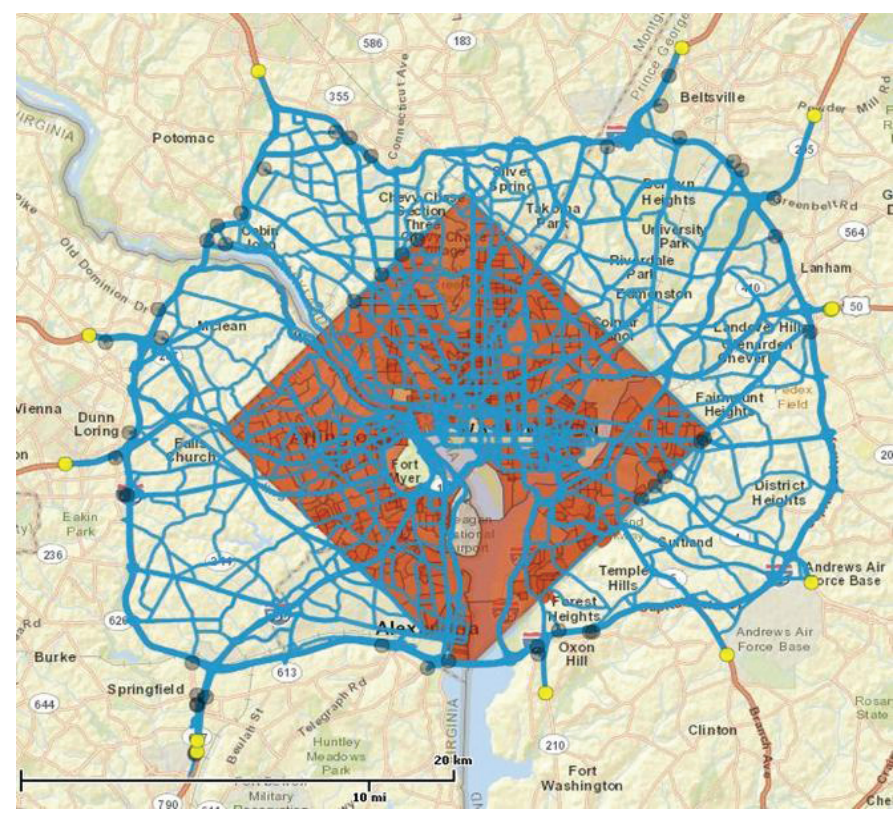

(a)

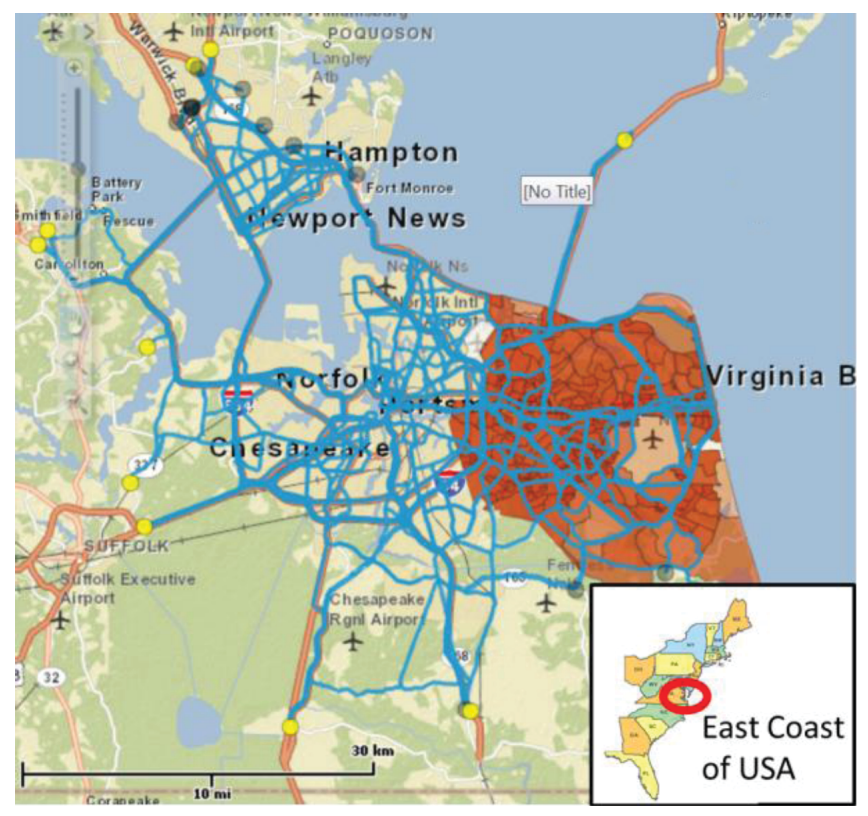

(b)

FIGURE 1 Screen shots from RtePM illustrating road networks and evacuated areas for study scenarios: (a) Washington, D.C. (simulation's shaded central square also includes adjacent areas in Arlington County, Virginia, and a portion of Alexandria, Virginia), and (b) Virginia Beach. 
basis of U.S. Census data, the population expected to evacuate was 431,000 nighttime, nonseasonal residents (Figure $1 b$ ). The microsimulation evacuated 172,000 vehicles, with an average vehicle occupancy of 2.5 people, through nearly 2,500 road segments to nine endpoints. The RtePM estimated the evacuation would take $13.7 \mathrm{~h}$ with no incidents and an 8-h response time.

\section{Variables}

With the simulations conducted in stochastic mode, the RtePM automatically and uniformly varied several factors in the model, including acceleration rate, vehicle speed, and vehicle length. The researchers also uniformly varied three explanatory factors: evacuating population size, response rate, and incident rate type. Simulation runs consisted of permutations of the values for these variables. Because the RtePM is a stochastic simulation, each permutation was repeated 100 times.

\section{Evacuating Population Size}

The value for evacuating population size varied $\pm 2 \%$ following a normal distribution to reflect changing population size at any given time.

\section{Response Rate}

Following a truncated sigmoid-shaped evacuation response curve according to accepted distributions in emergency evacuation literature, the time for the last evacuees to depart varied from $1 \mathrm{~h}$ (mass exodus) to $23 \mathrm{~h}$ (slow evacuation over the course of a day) (34). The response rate variable was changed in hourly increments for the simulation runs. The final departure time determined the shape of the response curve. The sigmoid-shaped departure time often is represented in evacuation literature by the Rayleigh distribution, in which $\beta$ is adjusted on the basis of the situation to represent the mode of the distribution function (35).

$p(t)=1-\exp \left[-0.5\left(\frac{t}{\beta}\right)^{2}\right]$

where $p(t)$ equals the probability density function for the Rayleigh distribution and $t$ is an arbitrary variable.

\section{Incident Rate Type}

Traffic incidents occurred at a given probability per VMT, which is defined as the total number of miles traveled by all vehicles while on the segment for some set period, usually $1 \mathrm{~h}$. [Collins et al. present the derivation, justification, and validation of the incident model (23).] This simple traffic incident model was tested statistically to follow a negative binomial distribution that is the expected distribution for traffic incidents $(9,23)$. Variations in the expected incident-to-accident ratio and rounding errors in the data used to derive the incident model required the definition of low, medium, and high incident rates, with expected incident rates at $0.905,1.000$, and 1.291 per $100,000 \mathrm{VMT}$, respectively (36; R. Margiotta, personal communication, Oct. 9, 2011). These incident rate types were coded 1,2 , and 3 , respectively, in the regression analysis; no incidents were coded 0 .

\section{RESULTS}

The results from the simulation runs are presented as correlation statistics and multivariate linear regression models. The RtePM simulation runs were conducted on a dedicated networked computer cluster that is available through the RtePM website. The focus of these results is on the macro-level effects of traffic incident rates on the overall evacuation time.

\section{Scenario 1. Washington, D.C.}

The Washington, D.C., scenario, hereafter referred to as the NCR scenario, was simulated 4,800 times; results of these runs are listed in Tables 1 and 2. The dependent variable in these runs is evacuation duration (i.e., time in hours for an evacuation to complete), and the independent variables are the total number of traffic incidents occurring during each run and the three explanatory variables described earlier.

The ordinary least squares (OLS) method was used to determine the parameters of the linear regression models. To confirm the assumption of independent explanatory variables required of the OLS method, the authors tested for statistically significant linear correlation with the Pearson correlation coefficient.

Evacuation duration has a statistically significant relationship with each of the variables included in the original analysis. Of these, only the response rate variables have a nearly perfect positive linear relationship with the dependent variable; the others have a negligible linear relationship (near zero) and thus can be used with the OLS

TABLE 1 Correlation Between Variables for NCR Scenario

\begin{tabular}{|c|c|c|c|c|}
\hline Variable & $\begin{array}{l}\text { Incident } \\
\text { Rate Type }\end{array}$ & $\begin{array}{l}\text { Response } \\
\text { Rate }\end{array}$ & $\begin{array}{l}\text { Evacuating } \\
\text { Population } \\
\text { Size }\end{array}$ & $\begin{array}{l}\text { Total } \\
\text { Incidents }\end{array}$ \\
\hline Evacuation duration & $0.057^{a}$ & $0.939^{a}$ & $-0.091^{a}$ & $-0.055^{a}$ \\
\hline Incident rate type & na & 0.000 & -0.007 & $0.939^{a}$ \\
\hline Response rate & na & na & $-0.095^{a}$ & $-0.113^{a}$ \\
\hline $\begin{array}{l}\text { Evacuating } \\
\text { population size }\end{array}$ & na & na & na & 0.004 \\
\hline
\end{tabular}

NoTE: na = not applicable.

${ }^{a}$ Statistically significant at $99 \%$ confidence level.

TABLE 2 Linear Regression Coefficients for NCR Scenario for Both Models

\begin{tabular}{lllll}
\hline Model & Coefficient & $\begin{array}{l}\text { Standard } \\
\text { Error }\end{array}$ & $t$-Statistic & $P$-Value \\
\hline Total Incidents & & & & \\
\hline Intercept & 6.597 & 0.059 & 111.620 & $<.001^{a}$ \\
Response rate & 0.638 & 0.003 & 191.058 & $<.001^{a}$ \\
Total incidents & 0.012 & 0.001 & 10.258 & $<.001^{a}$ \\
\hline Incident Rates & & & & \\
\hline Intercept & 6.622 & 0.055 & 120.158 & $<.001^{a}$ \\
Response rate & 0.634 & 0.003 & 191.674 & $<.001^{a}$ \\
Incidents rate type & 0.237 & 0.020 & 11.617 & $<.001^{a}$ \\
\hline
\end{tabular}

${ }^{a}$ Statistically significant at $99 \%$ confidence level. 
linear regression method. The total incidents and incident rate variables also have strong, statistically significant positive linear relationships, which is not surprising because they measure essentially the same phenomenon in the model. Because of their strong relationship, the two variables were not included in the same model; rather, two regression models were constructed for each scenario: one with incident rate, the other with total incidents. Evacuating population size also was eliminated from the model after initial linear regression results showed that it was not statistically significant.

\section{Regression Model with Total Incidents}

Results of the regression model including the total incidents variable for the NCR scenario are summarized in the top half of Table 2. The adjusted $R^{2}$-value- appropriate for models with multiple independent variables - indicates that $88.4 \%$ of variation in the simulation data is explained by the model that includes response rate and total incidents as independent variables (33). According to the standard error value (1.587) of the model, approximately $68.2 \%$ of the regression model estimates are within approximately $1.5 \mathrm{~h}$ of the actual evacuation duration for the RtePM simulation runs; $95.4 \%$ are within $3 \mathrm{~h}$.

\section{Regression Model with Incident Rate}

The second regression model for the NCR scenario incorporated incident rate instead of total incidents; results are shown in the bottom half of Table 2 . The adjusted $R^{2}$-value (.885) and standard error (1.582) are close to the values in the previous model, indicating that both models explain evacuation duration similarly. This result is important because the total incidents variable depends on the simulation run, whereas incident rate and response rate do not. The use of incident rate and response rate allows predictions about evacuation duration that would be generated by the simulation without actually running the simulation; it is particularly useful for an emergency planner who might not have the time or resources available to run the full simulation but is required to make predictions about evacuation of the NCR region.

The equation derived for the regression model of evacuation duration $(Y)$ for the NCR scenario with incident rate is

$Y=6.622+0.634 X_{\mathrm{RR}}+0.237 X_{\mathrm{IR}}$

where $X_{\mathrm{RR}}$ is the response rate and $X_{\mathrm{IR}}$ is the incident rate.

\section{Scenario 2. Virginia Beach}

The Virginia Beach scenario, hereafter referred to as the HR scenario, was simulated for 5,350 runs. Tables 3 and 4 summarize the findings for the Pearson correlation coefficient and regression results, respectively. As in the NCR scenario, the explanatory variables are sufficiently independent of each other (except for incident rate and total incidents), thus satisfying the assumptions of the OLS method.

\section{Regression Model with Total Incidents}

The model for the HR scenario incorporating the total incidents variable explained approximately $87.4 \%$ of the variance in evacua-
TABLE 3 Correlation Between Variables for HR Scenario

\begin{tabular}{|c|c|c|c|c|}
\hline Variable & $\begin{array}{l}\text { Incident } \\
\text { Rate Type }\end{array}$ & $\begin{array}{l}\text { Response } \\
\text { Rate }\end{array}$ & $\begin{array}{l}\text { Evacuating } \\
\text { Population } \\
\text { Size }\end{array}$ & $\begin{array}{l}\text { Total } \\
\text { Incidents }\end{array}$ \\
\hline Evacuation duration & $0.048^{a}$ & $0.910^{a}$ & $-0.035^{a}$ & $0.060^{a}$ \\
\hline Incident rate type & na & $-0.116^{a}$ & 0.001 & $0.953^{a}$ \\
\hline Response rate & na & na & $-0.063^{a}$ & $-0.116^{a}$ \\
\hline $\begin{array}{l}\text { Evacuating } \\
\text { population size }\end{array}$ & na & na & na & 0.005 \\
\hline
\end{tabular}

${ }^{a}$ Statistically significant at $99 \%$ confidence level.

TABLE 4 Linear Regression Coefficients for HR Scenario for Both Models

\begin{tabular}{lclrl}
\hline Model & Coefficient & $\begin{array}{l}\text { Standard } \\
\text { Error }\end{array}$ & $t$-Statistic & $P$-Value \\
\hline Total Incidents & & & & \\
\hline Intercept & 10.953 & 0.040 & 270.917 & $<.000^{a}$ \\
Response rate & 0.436 & 0.002 & 188.256 & $<.000^{a}$ \\
Total incidents & 0.024 & 0.001 & 33.511 & $<.000^{a}$ \\
\hline Incident Rates & & & & \\
\hline Intercept & 11.085 & 0.039 & 283.289 & $<.000^{a}$ \\
Response rate & 0.433 & 0.002 & 185.032 & $<.000^{a}$ \\
Incidents rate type & 0.444 & 0.014 & 31.781 & $<.000^{a}$ \\
\hline
\end{tabular}

${ }^{a}$ Statistically significant at $99 \%$ confidence level.

tion duration on the basis of the adjusted $R^{2}$-value and had a standard error of 1.125 .

\section{Regression Model with Incident Rate}

Similarly, the model for the HR scenario with the incident rate variable accounted for $87.1 \%$ of the variance in evacuation duration and had a standard error of 1.135. Despite being lower than the $R^{2}$ values for the NCR scenario, these values still imply that the regression model explains a large amount of variability. The regression model of evacuation duration for the HR scenario with incident rate is

$Y=11.085+0.433 X_{\mathrm{RR}}+0.444 X_{\mathrm{IR}}$

\section{Scenario Comparison}

Even though the population in the NCR scenario is almost twice that in the HR scenario, the expected evacuation duration, without incidents, in the NCR scenario is about $3 \mathrm{~h}$ shorter. This difference is largely a result of severe bottlenecks that arise in the HR scenario, in which evacuees can flee only northward or westward; in the NCR scenario, the population can evacuate in any direction. This logistic discrepancy is reflected in the regression models of the two scenarios.

The larger response rate coefficient in the NCR scenario indicates that it has a greater effect than in the HR scenario. Conversely, the incident rate coefficient in the NCR scenario is smaller, indicating that changes in the response rate have a smaller effect than in the 
HR scenario. The explanation for this phenomenon is that evacuees to the NCR have more alternative routes available if they encounter congestion resulting from a traffic incident, thus avoiding the severe bottlenecks of the HR area.

Regression models indicate that, under normal incident rates, evacuation duration will increase as a result of traffic incidents approximately $8.0 \%$ in the HR scenario and $7.2 \%$ in the NCR scenarios (with a medium incident rate, indexed as 2). Increases in evacuation duration seem insignificant at first but are not uniform across all evacuees. A few evacuees are significantly affected by traffic incidents, but those with alternative routes may experience little extra delay. Even a small increase in evacuation duration is critical in certain emergencies (e.g., radioactive cloud from a dirty bomb, in which case minimizing exposure is vital).

The general similarities between the two regression models could be used to predict evacuation duration in other scenarios. However, these models have several limitations. First, any model predictions could be done only within the independent variable range of this study. For example, the model considers only a $2 \%$ variability of the total evacuating population; larger variability would likely increase the significance of evacuating population size in the multivariate regression model. Second, the regression models in this study represent RtePM simulation data and cannot necessarily account for the variability of real-world evacuation duration; panic from certain types of events, for example, might cause considerable variability (13). Other factors, such as heteroscedasticity (e.g., intergroup variation among evacuees such as elderly, families, and tourists who may follow indirect evacuation routes to assist family members or because of unfamiliarity with the roads), were not considered in this analysis.

The proposed approach is novel because it produces a regression metamodel of the effects of traffic incidents on evacuation duration. Because of the novelty of this analysis, little real-world data and few other evacuation simulation results exist to compare findings. Robinson and Khattak construct a similar scenario for the HR area with the Citilab Cube simulation engine, the Avenue plug-in, and facility-dependent incident data as opposed to the generic incident approach used in this model (21). They find that traffic incidents increase evacuation duration by about $10 \%$, slightly more than the $8.0 \%$ estimate in the present model. The similarity between results helps validate the present generic approach to incident modeling.

\section{DISCUSSION OF RESULTS}

This purpose of this paper is to provide potential users with simple models to predict the effects of incident rates on an emergency evacuation. The low data requirements of this approach should benefit those who do not have the luxury of time or budgetary resources to acquire the data needed to implement other approaches to the problem. For example, even though extensive traffic incident data are collected in the NCR, only data-sharing coalition members have access.

The authors do not suggest that these models are appropriate for all purposes. The incident model and RtePM are intended for rapid, reasonably accurate modeling of evacuations in the United States, including Alaska and Hawaii. The regression models presented provide emergency planners with quick, non-data-intensive insight into and analysis of the effects of traffic incidents during large-scale evacuations.

\section{CONCLUSIONS}

This paper investigated the effects of traffic incidents on the duration of an emergency evacuation. Multivariate regression models of Virginia Beach and Washington, D.C., were developed to quantify this effect. Results used for the regression model come from simulation runs of the RtePM microsimulation model. Regression models of the two scenarios account for a large portion of variability in the evacuation duration of each region. The regression models indicated an $8.0 \%$ increase in evacuation duration for the HR scenario and a $7.2 \%$ increase for the NCR scenario, confirming previous work in the HR region (21). The difference between the two scenarios was attributed to the limited number of alternative evacuation routes available to HR evacuees, which resulted in traffic bottlenecks that extended the duration of evacuation. Incidents at bottlenecks caused vehicles to divert to longer travel routes.

The proposed model provides emergency managers with estimates of evacuation duration under similar conditions and hazards. Any such application would be feasible only for a limited range of independent variables (e.g., the evacuating population would have to be within $2 \%$ of the total population). The multivariate regression models do not account for human behavioral effects such as panic; investigating these effects currently is an unresolved research area. Future work will apply this analysis to other scenarios to develop regional and situational comparisons as well as generalizations helpful to emergency planning managers. Future models also will incorporate factors beyond the VMT and behavioral factors such as panic and differences in how certain evacuee groups (e.g., elderly and tourists) might affect the evacuation outcome.

\section{ACKNOWLEDGMENTS}

The authors are grateful to the team at the Johns Hopkins University Applied Physics Laboratory and to Janet Clements of the All Hazards Consortium for support in the further development of the RtePM model. The authors thank Cambridge Systematics and Rich Margiotta of the Transportation Research Board's Strategic Highway Research Program 2 (SHRP 2) for assistance with data. This work was funded by a U.S. Department of Homeland Security Regional Catastrophic Preparedness Grant through the Virginia Department of Emergency Management.

\section{REFERENCES}

1. Matherly, D., J. Mobley, B. Wolshon, J. Renne, R. Thomas, and E. Nichols. NCHRP Web-Only Document 196: Final Research Report: A Transportation Guide for All-Hazards Emergency Evacuation. Transportation Research Board of the National Academies, Washington, D.C., 2012

2. Manual on Classification of Motor Vehicle Traffic Accidents, 7th ed ANSI D16.1-2007. American National Standards Institute, Washington, D.C., 2007.

3. Jovanovic, D., T. Backalic, and S. Basic. The Application of Reliability Models in Traffic Accident Frequency Analysis. Safety Science, Vol. 49 No. 8-9, 2011, pp. 1246-1251.

4. Al-Harbi, M., M.F. Yassin, and M. B. Shams. Stochastic Modeling of the Impact of Meteorological Conditions on Road Traffic Accidents. Stochastic Environmental Research and Risk Assessment, Vol. 26, No. 5 , 2012, pp. 739-750.

5. Chen, K. M., L.F. Xie, and W.S. Xiang. Traffic Accidents Prediction Using Improved Grey-Markov Model. Advanced Materials Research: Applied Materials and Electronics Engineering, Vol. 378-379, 2012, pp. 222-225. 
6. Chen, Y., and D. Xiao. Evacuation Model and Algorithms for Emergency Management System. Proc., International Conference on Transportation Engineering 2007, American Society of Civil Engineers, Reston, Va., pp. 3171-3177.

7. Collins, A. J., K. B. Vegesana, M. J. Seiler, P. O'Shen, P. Hettiarachchi, and F. McKenzie. Simulation and Mathematical Programming DecisionMaking Support for Smallholder Farming. Environment Systems and Decisions, Vol. 33, No. 3, 2013, pp. 427-439.

8. Abdel-Aty, M.A., and A. E. Radwan. Modeling Traffic Accident Occurrence and Involvement. Accident Analysis and Prevention, Vol. 32, No. 5, 2000, pp. 633-642.

9. Huang, H.L., H. C. Chin, and M.M. Haque. Bayesian Hierarchical Analysis of Crash Prediction Models. Presented at 87th Annual Meeting of the Transportation Research Board, Washington, D.C., 2008.

10. Murray-Tuite, P. M., and H.S. Mahmassani. Methodology for Determining Vulnerable Links in a Transportation Network. In Transportation Research Record: Journal of the Transportation Research Board, No. 1882, Transportation Research Board of the National Academies, Washington, D.C., 2004, pp. 88-96.

11. Liu, Y., X. Lai, and G.-L. Chang. Two-Level Integrated Optimization System for Planning of Emergency Evacuation. Journal of Transportation Engineering, Vol. 132, No. 10, 2006, pp. 800-807.

12. Pel, A. J., S. P. Hoogendoorn, and M. C. J. Bliemer. Impact of Variations in Travel Demand and Network Supply Factors for Evacuation Studies. In Transportation Research Record: Journal of the Transportation Research Board, No. 2196, Transportation Research Board of the National Academies, Washington, D.C., 2010, pp. 45-55.

13. Wang, J., S. Lo, J. Sun, Q. Wang, and H. Mu. Qualitative Simulation of the Panic Spread in Large-Scale Evacuation. Simulation, Vol. 88, No. 12 , 2012, pp. 1465-1474.

14. Robinson, R.M., and A.J. Khattak. Route Change Decision Making by Hurricane Evacuees Facing Congestion. In Transportation Research Record: Journal of the Transportation Research Board, No. 2196, Transportation Research Board of the National Academies, Washington, D.C., 2010, pp. 168-175.

15. Robinson, R.M., and A. Khattak. Evacuee Route Choice Decisions in a Dynamic Hurricane Evacuation Context. In Transportation Research Record: Journal of the Transportation Research Board, No. 2312, Transportation Research Board of the National Academies, Washington, D.C., 2012, pp. 141-149.

16. Robinson, R. M. Modeling Decision Making Related to Incident Delays During Hurricane Evacuations. PhD dissertation. Old Dominion University, Norfolk, Va., 2010.

17. Robinson, R. M., A. J. Khattak, J.A. Sokolowski, P. Foytik, and X. Wang. Role of Traffic Incidents in Hampton Roads Hurricane Evacuations. Presented at 88th Annual Meeting of the Transportation Research Board, Washington, D.C., 2009.

18. Murray-Tuite, P.M., and H.S. Mahmassani. Model of Household TripChain Sequencing in Emergency Evacuation. In Transportation Research Record: Journal of the Transportation Research Board, No. 1831, Transportation Research Board of the National Academies, Washington, D.C., 2003, pp. 21-29.

19. Quarantelli, E.L. Research Findings on Organizational Behavior in Disasters and Their Applicability in Developing Countries. Preliminary paper 107. Disaster Research Center, University of Delaware, Newark, 1986. http://dspace.udel.edu:8080/dspace/handle/19716/481. Accessed Jan. 1, 2013.

20. Quarantelli, E. L. Disaster-Related Social Behavior: Summary of 50 Years of Research Findings. Preliminary paper 280. Disaster Research Center,
University of Delaware, Newark, 1999. http://dspace.udel.edu:8080/ dspace/handle/19716/289. Accessed Jan. 1, 2013.

21. Robinson, R.M., and A. Khattak. Selection of Source and Use of Traffic Information in Emergency Situations. In Transportation Research Record: Journal of the Transportation Research Board, No. 2234, Transportation Research Board of the National Academies, Washington, D.C., 2011, pp. 71-78.

22. Injury Facts. National Safety Council, Itasca, Ill., 2011. http://www.nsc. org/Documents/Injury_Facts/Injury_Facts_2011_w.pdf. Accessed Jan. 1, 2013.

23. Collins, A. J., R. M. Robinson, C. A. Jordan, P. Foytik, and B. C. Ezell. Generic Incident Model for Use in Large-Scale Evacuation Simulations. Proc., IEEE International Conference on Technologies for Homeland Security, Waltham, Mass., Nov. 12-14, 2013.

24. Highway Safety Manual. AASHTO, Washington, D.C., 2010, pp. 2.11-2.15

25. McCartt, A.T., V.S. Northrup, and R.A. Retting. Types and Characteristics of Ramp-Related Motor Vehicle Crashes on Urban Interstate Roadways in Northern Virginia. Journal of Safety Research, Vol. 35, No. 1, 2004, pp. 107-114.

26. Milton, J., and F. Mannering. The Relationship Among Highway Geometrics, Traffic-Related Elements and Motor-Vehicle Acciden Frequencies. Transportation, Vol. 25, No. 4, 1998, pp. 395-413.

27. Deublein, M., M. Schubert, B. T. Adey, J. Köhler, and M. H. Faber. Prediction of Road Accidents: A Bayesian Hierarchical Approach. Accident Analysis and Prevention, Vol. 51, 2013, pp. 274-291.

28. Haynes, R., A. Jones, V. Kennedy, I. Harvey, and T. Jewell. District Variations in Road Curvature in England and Wales and Their Association with Road-Traffic Crashes. Environment and Planning A, Vol. 39, No. 5, 2007, pp. 1222-1237.

29. Wang, C., M. Quddus, and S. Ison. The Effects of Area-Wide Road Speed and Curvature on Traffic Casualties in England. Journal of Transport Geography, Vol. 17, No. 5, 2009, pp. 385-395.

30. Haynes, R., I. R. Lake, S. Kingham, C.E. Sabel, J. Pearce, and R. Barnett. The Influence of Road Curvature on Fatal Crashes in New Zealand. Accident Analysis and Prevention, Vol. 40, No. 3, 2008, pp. 843-850.

31. Nielsen, E., and T. Cole. Independent Verification and Validation (IV\&V) of Real Time Evacuation Planning Model (RtePM). DDL Omni Engineering, Virginia Beach, Va., 2013.

32. Russell, S., and P. Norvig. Artificial Intelligence: A Modern Approach, 2nd ed. Prentice Hall, Upper Saddle River, N.J., 2002.

33. Everitt, B. S., and G. Dunn. Applied Multivariate Data Analysis, 2nd ed. Wiley, New York, 2010.

34. Radwan, A.E., A. G. Hobeika, and D. Sivasailam. A Computer Simulation Model for Rural Network Evacuation Under Natural Disaster. Institute of Transportation Engineers Journal, Vol. 55, No. 9, 1985 , pp. 25-30.

35. Lindell, M., and C. Prater. Critical Behavioral Assumptions in Evacuation Time Estimate Analysis for Private Vehicles: Examples from Hurricane Research and Planning. Journal of Urban Planning and Development, Vol. 133, No. 1, 2007, pp. 18-29.

36. Chapter 36: Travel Time Reliability. In Highway Capacity Manual 2010 Volume 4. Draft release, September 2012. Transportation Research Board of the National Academies, Washington, D.C., forthcoming.

The Critical Transportation Infrastructure Protection Committee peer-reviewed this paper. 